Notre Dame Law School

NDLScholarship

Natural Law Forum

$1-1-1966$

\title{
What the Philosopher May Learn from the Study of Law
}

Ch. Perelman

Follow this and additional works at: http://scholarship.law.nd.edu/nd_naturallaw_forum Part of the Law Commons

\section{Recommended Citation}

Perelman, Ch., "What the Philosopher May Learn from the Study of Law" (1966). Natural Law Forum. Paper 114. http://scholarship.law.nd.edu/nd_naturallaw_forum/114

This Article is brought to you for free and open access by NDLScholarship. It has been accepted for inclusion in Natural Law Forum by an authorized administrator of NDLScholarship. For more information, please contact lawdr@nd.edu. 


\section{WHAT THE PHILOSOPHER MAY LEARN FRIOM THE STUDY OF LAW*}

Ch. Perelman

At the entrance of the Academy, Plato had placed the inscription: "No one may enter unless he be trained in geometry"; in the same fashion, Descartes and Spinoza proposed the geometrical method to philosophers as a model of rationality. Leibniz dreamt of being able to terminate philosophical disputes by having recourse to counting - calculemus - and hoped to put an end to differences of opinion among philosophers by means of those procedures which bring mathematicians to agreement. Other thinkers with empirical tendencies, from Hume to Piaget, have proposed that philosophers follow the methods of the experimental sciences.

On the other hand, I know of hardly any philosopher who has proposed that one draw inspiration from the juridical model. On the contrary, philosophers, traditionally, at least the rationalists, have not hesitated to express their scorn for law, its techniques and its practitioners. Instead of endlessly discussing the shadowy images of the just, Plato aspired to furnish us with the knowledge of true justice, which would enable the dialectician, who alone is qualified to involve himself with politics, to find rational solutions to any problem of justice.

It is worth noting that in all the utopian cities, which are supposedly rational, no place is reserved for the practitioners of law, even when these cities are the creations of jurists. This stands out clearly from the interesting paper, presented by my colleague Paul Foriers, at the Brussels conference on Les Utopies à la Renaissance: 1

Constructors of ideal cities or visionary reformers, the Utopians drew plans which, by their very perfection, reduced the place of law, its role and its influence.

Because it is harmonious, the ideal city knows hardly any dissonances.

- This paper is a revised version of a talk given at the tenth annual meeting of the Board of Editors of the Natural LAw Forum. The same theme, developed differently, was dealt with in my article Ce qu'une réflexion sur le droit peut apporter au philosophe, in Les Archives de Philosophie du Droit (Paris, 1962), reproduced in Ch. PerelMaN, Justice et Raison 244-255 (1963).

1 P. Foriers, Les Utopies et le Droit, in Les Utopies i La Renaissance 233-261 (1963). 
Conflicts would thus be accidents, which utopian optimism would sec only as such. Their multiplication would be avoided, such optimism believes, by condemning the jurists as a group and putting faith in the pre-excellence of human nature. ${ }^{2}$

In utopian countries there are only a few laws; simple and clear, they are immediately accessible to everyone and do not need to be interpreted in order to be understood: "No lawyers from now on. Far from viewing them as instruments of justice there, the Utopians regarded professional pleaders as men intent on twisting the meaning of the law and living by chicanery."3 This is certainly the opinion of Thomas More, in his Utopia, and Eméric Crucé, in Le Nouveau Cynée, does not hesitate to accuse the lawyers of perverting the law:

The text of the laws is clear and intelligible. If there is something lacking, let the judges supply it with their wisdom and equity, without recourse to a thousand interpreters who agree no more amongst themselves than do clocks and who cause scruples and distractions of the spirit by the diversity of their opinions. It is this which engenders and nourishes litigations and makes them last so long that the end is lost from sight. This is why the Spanish peoples in the Indies were correct in begging their king not to send them any lawyers. Primitive people living naturally are more at ease than those who employ their subtlety in trickery. ${ }^{4}$

One hopes that in the ideal city the laws will be inscribed in the heart, conscience, and reason of each person; that each person's conduct will conform to them spontaneously; and that one will need neither judges nor lawyers. Does one imagine tribunals in Paradise?

The diversity of laws, their variation in time and space, provoked Pascal's celebrated comment:

Three degrees elevation of the pole upsets all jurisprudence; a meridian determines truth; after a few years' possession the fundamental laws change; law has its periods; Saturn entering Leo shows us the origin of a certain crime. Merry justice which is limited by a river! Truth this side of the Pyrenees, error on the other. ${ }^{5}$

The diversity of laws is proof of our ignorance of true justice. That which conforms to reason cannot be just here and unjust there, just today and unjust

2 Id. at $234-235$.

3 Id. at 239 .

4 Emeric Crucé, Le Nouveau Cynée ou Discours d'Etat représentant les OCCASIONS ET MOYENS D'ESTABLIR UNE PAIX GÉNÉRALE, ET LA LIBERTÉ DU COMMERCE PAR TOUT LE MONDE 167 (1623), cited by Foriers, op. cit. supra note 1, at 240.

5 Blaise Pascal, Pensées 69, 365 (ed. Brunschvicg, 193-). 
tomorrow, just for one and unjust for another. That which is just in reason should, like that which is true, be so universally. Disagreement is a sign of imperfection, of a lack of rationality.

If two interpretations of the same text are reasonably possible, it is because the law is ambiguous, therefore imperfect. If the law is clear, then at least one of the two interpreters disputes in bad faith. In any case, disagreement is a scandal, due either to the imperfection of the legislator or to the deceptive subtlety of the lawyers. The innate sense of justice, which each equitable judge certainly possesses, should permit the rapid reestablishment of correct order.

In the ideal city, where everything is rationally organized, the laws cannot present these defects; and lawyers who are too subtle must be removed from positions where they might be injurious. Why should not the agreement which is observed as to mathematical axioms and theorems be achieved in law? Divine reason in its omniscience knows the true and the just in all things: should not men, therefore, in conformity with divine reason, extend to all matters that clear and distinct knowledge which is the glory of geometry?

But what do we observe? The ideal of a natural or rational law, which would impose itself on everyone like a system of geometry, gave rise to highly divergent systems. Locke had already noted the paradox that the articles of codes, which appeared clear to the uninitiated, were plunged into obscurity, following their elucidation by commentators. ${ }^{6}$

Must one attribute this state of affairs, whose existence cannot be denied, to the irrationality or the dishonesty of jurists? Must one condemn the law and the jurists in the name of a conception of reason and justice inspired by mathematical or natural sciences, or should one not begin with the fact that the most eminent jurists are as reasonable and as honest as men of science, and accept once and for all that the divergencies of all sorts which one observes in law stem from its own nature, from its specificity in comparison to the sciences? If the important decisions of the Supreme Court of the United States are rarely made unanimously, must one accuse at least certain of these respected judges of being unreasonable or dishonest, or must one not conclude that in law discord is explained by specific reasons? The Jewish tradition, which never sought to conceive law on the scientific model, offers a significant story in this connection. In the Talmud two schools of biblical interpretation are in constant opposition, the school of Hillel and that of Shammai. Rabbi Abba relates that, bothered by these contradictory interpretations of the sacred texts, Rabbi Samuel addresses himself to heaven in order to know who speaks the truth. A Voice

' John Locke, An Essay on Human Understanding III, ix, 9. (p. 389, 1900 ed.). 
from above answers him that these two theses both expressed the word of the Living God. ${ }^{7}$ The lesson of this story is clear: two opposing interpretations can be equally respectable, and it is not necessary to condemn as unreasonable at least one of the interpreters.

In fact, we admit that two reasonable and honest men can disagree on a determined question and thus judge differently. The situation is even considered so normal, both in legislative assemblies and in tribunals which have several judges, that decisions made unanimously are esteemed exceptional; moreover, it is normal to provide for procedures permitting the reaching of a decision when opposing opinions persist.

But because the juridical practices of all peoples recognize this state of affairs, must one condemn the law in the name of criteria which are alien to it, or can one not, on the contrary, gain profit from an analysis of the specificity of law in order to better understand other situations where irreducible divergencies manifest themselves, as in ethics, politics, and philosophy?

Law, as it functions in fact, is essentially a problem of decision: the legislator must decide what will be the obligatory laws in an organized community, the judge must decide what is the law in each situation submitted to his judgment. But neither the legislator nor the judge makes purely arbitrary decisions: the statement of motives indicates the reasons for which a law was voted and, in a modern system, each judgment should be accounted for in terms of the law. Positive law has as a correlative the notion of a decision, which, even if not rational in the sense of its conformity to formal deduction, should be reasonable or at least reasoned.

Those philosophies which take the sciences as a model leave no room for the idea of rational decision. They are built in terms of the idea of truth, either certain or probable. Before truth there is no place for rational choice, because all choice, in that perspective, implies ignorance of the truth. To be reasonable is to make one's ideas conform to an objective reality or to present them in such a way that their clarity and their distinctiveness impel us to submit to the evidence. The possibility of choosing is then correlative to ignorance of the unique response, of the response which God has known from all eternity.

Classical rationalism, that of Descartes and Spinoza, studying the relationships of reason and will, was inspired by an absolute model. In taking this model, it falsified the actual relationships which exist between these faculties by eliminating, in the final analysis, one of them in favor of the other.

7 The Babyzonian Talmud, Seder Mold 2, Erubin 136 (ed. by Epstein); cf. Ch. Perelman, Désaccord et rationalité des décisions, Arcervio di Filosopia 87-93 (1966). 
Divine perfection can, in fact, be envisaged either as perfect will or as omniscient reason.

Perfect will does not find itself confronted by any reality or any norm: what it decides becomes, by the fact itself, reality, truth and justice. Divine will is, for Descartes, the creator of the real and the foundation of all the norms, for nothing is able to limit its omnipotence or its perfection. But this will is purely arbitrary because it does not need to conform to any criterion outside itself.

For Spinoza, divine reason is consciousness of a systematic order, all the propositions of which are theorems linked together in a rigorous fashion. Inasmuch as man is rational and conforms to his clear and distinct ideas, he is free. But his freedom, being identified with the order of reason, does not contain a place reserved for any power of decision or choice.

In the conception of Descartes, just as in that of Spinoza, there is no possibility of an imperfect but rational choice for human will which sceks to avoid error and evil. Such a choice, which is not arbitrary but guided by rules, presupposes the exercising of a power of decision within a preestablished framework. This double condition is as much opposed to the idea of a perfect will, criterion of all norms, as it is to that of perfect reason, capable of determining the unique correct solution of all problems, and thus eliminating all possibility of an enlightened choice.

The traditional role of law is to organize effectively and in various ways the dialectics of imperfect human will and human reason. It contrasts with the divine model of the rationalists which is inadequate precisely where it admits no room for the idea of rational decision. 8

It was the geometrical method which inspired the classical rationalists with the ideal of reason. Beginning with self-evident axioms, imposing themselves on every rational person by means of rules of deduction equally undoubtable, a man is able to transfer the evidence of the axioms to all the theorems. Divine reason being capable of knowing the truth or the falschood of every proposition, it is an understandable ideal to propose that men find, by correct use of the geometrical method, the truths which God has known throughout all eternity. By dismissing all the opinions about which there could be the slightest doubt, Descartes hopes to arrive at self-evident truths which, like a solid rock, will permit the founding of an unshakable philosophical system, serving as a basis for the universal community of rational beings. This ideal of rationality supposes humanity purged, through doubt, of all the prejudices, dogmas, values, and norms which a long history has deposited in the conscience of each constituted society. Any axiomatic system presents itself, in the same fashion.

${ }^{8}$ Cf. Ch. Pegrelman, Justice et Raison 246-47 (1963). 
as independent of all context: whether we should consider the axioms as evident or as arbitrary (and the will of the mathematician is supposed, in this case, in the manner of the divine will, not to know any obstacle and to determine both the first principles and the rules of inference), they are not, in the classical perspective, the object of a rational decision. Either the axioms impose themselves on the will of every rational being or, conforming to Carnap's principles of tolerance, each person elaborates, as he understands it, his axiomatic system. In the first case, conformity to reason eliminates all choice; in the second case, choice is arbitrary and without reason. This is why the axiomatic method, which is applied in geometry, and which served as a model for the classical rationalists, differs completely from juridical reasoning. We will see that by taking the latter as a model, one arrives at the conception of another type of rationality.

While Descartes wanted to construct his rational knowledge from the starting point of a universal doubt, marking a rupture with the past, all rationality for jurists is continuity. Rupture with preexisting order, the installation of a new regime, of a new constitutional power, can occur in history only by violence or at least by the threat of the use of force. It is an illusion to believe that a new order imposes itself by its rationality alone. When it is recognized as being rational, it is because it conforms to a criterion of rationality previously accepted, and because it does not represent a complete rupture with the past. A thesis like Kelsen's, developing the pure theory of law by considering the system of law as separated from all nonjuridical contexts, could at best be considered only as a hypothetical-deductive system, the validity of the fundamental norm or of the constitutional principles always being presupposed. But whence does the fundamental norm receive its validity? Certainly not by its being self-evident. The initial theses of a juridical system, whatever they may be, whether it is a question of constitutional principles, of laws, of judicial precedents in the common law system, or even of general principles of law, have never been considered as self-evident, as imposing themselves in an unambiguous fashion on all rational beings. But, on the other hand, neither have they ever been considered as arbitrary. Situated in a social, political, and historical context, they find, in this context, reasons which explain and justify their acceptance.

Acceptance of the fundamental theses of a juridical system is as rarely based on force alone as it is based on the self-evidence of the system. Ordinarily, what the clarity of juridical rules lacks is supplied by the authority of those who have presented them insofar as they are considered the legitimate possessors of constitutional or legislative power. 
Every revolution which ended with a change of regime and not simply with a change of persons within the same regime, was preceded by a period, more or less lengthy, which furnished ideological justification for the new constitutional principles. As for new laws, they are normally preceded by a statement of motives which indicates the reasons for which the laws have been advanced and admitted. By presenting the law as a means permitting the realization of certain previously accepted ends, an effort is made to show its legitimacy - not merely its legality, i.e., that it had been voted according to the forms provided by the juridical system. When the law sanctions only the traditional rules, practices, and customs of the society to which it is applied, it benefits at the outset from the adhesion accorded these rules. The morc legislation conforms to expectation, the less indispensable is recourse to authority in order to enforce it. Thus, for example, in 1919, the Belgian government was able to abolish the plural vote and establish egalitarian, universal suffrage (one man, one vote) by a means which violated the constitution in a flagrant fashion, but which corresponded so closely to the conceptions of the great mass of the population that the government's illegal action did not pose the least political problem, and the legitimacy of the measure appeared incontestable. ${ }^{9}$

The authority of judicial precedents in a society administered under common law, and, to a lesser degree, in any system of law in which legal decisions are published, is also founded on prejudice favoring conformity to past decisions.

As for the general principles of law, these express traditional values in the juridical consciousness of a given civilization. They formulate theses which the educated members of the society are tempted to admit spontancously, and thus closely approach self-evident principles which hardly need a particular authority to be admitted. Nevertheless, this authority is indispensable, inasmuch as these principles necessitate an interpretation and a delimitation of their field of application. The field of application can be much more controversial than the principles themselves, agreement on these having been achieved with ambiguity and vagueness.

The exigencies of the juridical order, which continues through all kinds of upheavals as long as it has not been entirely or partially replaced by a new order, clearly show us what is unfeasible in the advice of Descartes, asking us to make a tabula rasa of all our opinions. What normal man would put any one of his convictions into doubt if the reasons for doubt were not more solid than the opinion to which they were opposed? To dislodge a belief there is need, as with a lever, for a point of leverage more solid than what

9 See, for details, E. Cammarrts, Albert of Belgium, Defender of Rioht 312-25, $332-35,367$ (1935). 
is to be moved. Nobody has ever seriously put in doubt the totality of his opinions, for they test each other reciprocally: one keeps those which, up to the moment, have best resisted the testing. This, however, does not guarantee them absolutely against all subsequent tests. While in absolutist metaphysics the spirit oscillates from absolute doubt to absolute certainty, we are in reality always in the "in-between": the opinions to which we adherc constitute the last state of the evolution of our ideas, which does not signify necessarily a definitive state; but it would not be reasonable to abandon these ideas, unless they prove themselves to be incompatible with ideas to which we attach superior credit. To ask us to make a tabula rasa of our intellectual past is to act against the principle of inertia, upon which is founded, in fact, our spiritual life as well as our political and social organization. This principle manifests itself by the rule of justice, which asks us to treat in the same fashion beings and situations which are essentially similar, ${ }^{10}$ and, more particularly, by the conformity to precedents, which assures the continuity and the coherence of our thought and our action. One could formulate the principle of inertia as a directive: one should not change anything without reason. If one maintains that our ideas, our rules, and our behavior are devoid of an absolute foundation, and that for this reason, the pros and the cons are equally worthy, and that one must therefore in philosophy make a tabula rasa of our past, one expresses an exigency which comes from utopia and to which one can only conform fictitiously. It is true that even Descartes in his provisional ethic showed more realism, but must one, in order to build science and philosophy, adopt principles entirely opposed to those which are useful for the "actions of life"? I believe, on the contrary, that (all use of violence being excluded by principle) the totality of our ideas is transformed from within, as is a juridical order which, in order to function as it adapts itself to new situations and aspirations, provides for procedures ensuring flexibility and allowing for reform. ${ }^{11}$

Thus rationality, as it presents itself in law, is always a form of continuity - conformity to previous rules or justification of the new by means of old values. That which is without attachment to the past can only be imposed by force, not by reason. As a result, the new and the old do not have to be treated in the same fashion, i.e., they do not have to be accepted if they are selfevident and ruled out in the contrary case. For if this were the case, all rules of action, which are never self-evident, should be dismissed. Even Descartes recognized this as impossible, for he could not do without a provisional ethic. But

10 Cf. The Role of Justice in Ch. Perelman, The Idea of Justice and the Proplem of ARGUMENT 79-87 (1963).

11 Perelman, op. cit. supra note 8 , at 249-250. 
he did not see that it would be impossible for him to replace the provisional ethic with a definitive ethic, the principles of which would be both clear and self-evident.

Law teaches us, on the contrary, to abandon existing rules only if good reasons justify their replacement: only change requires justification, presumption playing in favor of what exists, just as the burden of proof falls upon him who wants to change an established state of affairs. If that which is new prevails rationally (and not by violence) it is because of the fact that it better satisfies preexisting criteria or exigencies.

Reasons which bring about the modification of an old rule, or its replacement by a new one, are not universally valid. They must, however, be admitted by those who need to be persuaded of the utility of the new legislation. In other words, as reliance cannot be put in the self-evidence of the rule, the statement of the motives must show its desirability in a given political context; the values and the norms which are actually admitted furnish the point of departure for the argument which should justify the introduction of the new rule.

But the argumentation which forms the statement of the motives does not in any way constitute a deduction, and the conclusion which it reaches is in no way constraining. The reasons in favor of the rule are arguments of greater or lesser strength to which reasons in an adverse sense, themselves arguments of greater or lesser strength, can normally be opposed. Actually, the values, the norms, and the facts from which an agreement stems are extremely varied, and the one who argues is obliged to choose among them. This choice will put a certain group of facts, this or that value, such and surh a norm in the foreground of consciousness by conferring on it a presence in the mind of the listeners. Certain of these given facts are going to become reformulated or reinterpreted in order to better illustrate the pertinence of the proposed measures and their suitability to the pursued goal. There will be an opportunity, should the occasion arise, to refute the objections and the criticisms of those who uphold other facts, other values, and other norms.

Thus in establishing, by new legislation, a system of old-age pensions, there would be occasion to show not only the utility of that form of insurance against misery, but also that the resulting burden to the community can be assumed without requiring the sacrifice of any other service which the community would judge more important. One can see that; on all these questions, and more particularly when it is a matter of determining the total pensions, different opinions are equally justified and perhaps even equally reasonable. When it is a question of establishing norms of action, no single solution exists which in such matters could impose itself on all the members 
of the community as self-evident. For this reason, as no decision can be recognized as the only reasonable one and, nevertheless, a decision must be made which will become obligatory, it is indispensable to determine who will have the power to make an authorized decision, to determine how legislative power will be conferred.

But the promulgation of laws does not suffice to render their application incontestable and uniform. Laws can usually be interpreted and applied in several ways: to avoid disorder, it is indispensable therefore, pursuant to certain procedures, to accord certain persons the power to govern, administer, and judge.

Laws are more or less clear, and they accord to those who apply them a more or less extensive power of interpretation. There is an inversely proportional relationship between the clarity of the law and the power of interpretation accorded to those who must apply it. This power becomes all the greater as with the evolution of society, technical progress, and the changes of mores, the letter of the law becomes more and more opposed to its spirit, that is, to the purpose it is supposed to realize. Must one accord preeminence to a formalistic and analytical interpretation of the law, which is more favorable to juridical security? On the contrary, must one accord primacy to a teleological and pragmatic interpretation of the law, which essentially would take into account consequences, involving questions of equality and the common good? Both approaches have their partisans, and for this reason the authority of a judge is indispensable in order to put an end to otherwise interminable controversies. Again, on this point, juridical reasoning is opposed to purely formal reasoning; in taking into account the consequences, the judge, and especially the supreme court, uses the power of interpretation which has been accorded to the judiciary to reinterpret the text of the law which it has been given to apply. The reasoning of the judge is dialectical and opposed to the analytical reasoning of mathematicians, which always goes in a single direction, from premises towards conclusions.

Authority, which is indispensable for the making of laws, governing and judging, is superfluous when it is a question of demonstrating a theorem of arithmetic or geometry. In fact, all those who have some knowledge of these matters are at least capable of checking the accuracy of a demonstration and, once the proof is admitted, they bow before the conclusion. If a formal system is coherent, the negation of a demonstrated thesis is necessarily false. There is no question, in a formal, usable system, of demonstrating the thesis and the antithesis. In law, on the contrary, one can plead pro and con, and two incompatible decisions can be equally reasonable. But in order that this affirmation be theoretically defensible, the idea of reason 
must not be linked to that of truth. ${ }^{12}$ The dissociation of these two notions is, moreover, indispensable in order that the idea of a rational decision be meaningful. What is a question of decision cannot be a question of truth. One must yield to truth; there is no room for deciding. I do not decide that two plus two make four or that Paris is the capital of France. A rational decision is not simply a decision conforming to truth, but rather that decision which can be justified by the best reasons, at least inasmuch as justification is necessary.

If there were an objective criterion, expressible in quantitative terms for example in terms of probability - of what in each case was the best reason, then a single judgment would be reasonable, namely, to conform one's behavior to the quantitatively determined result. But if the best reasons cannot be determined outside a world view which, once elaborated, produces a philosophy, then the existence of a plurality of irreducible philosophies makes it impossible to admit that, in all circumstances, a single decision merits the qualification of reasonable.

It is when the subject matter escapes the qualification of truc or false, because it does not depend upon a unitary science but upon a philosophical pluralism, that an attitude of tolerance is justified and that a dialogue, permitting the perspectives to be enlarged, is not only useful but even indispensable. Just as the judge, before making a decision, should hear the two sides - audiatur et altera pars - the adoption of a philosophical position, at the risk of lacking rationality, should take into account the opposed points of view concerning the subject matter.

When it is a question of decision, several theses are equally defensible, and none imposes itself with evidence. Hence, from this point on, an authority is indispensable to render certain decisions obligatory. It is because the elaboration and the application of the norms usually bring about divergencies that it is indispensable to know who has the power of making laws and who is competent to judge and terminate conflicts. But the obligation, which law has taught us, to establish authorities in these matters, reveals the fact that one does not find oneself confronted by truths which impose themselves upon every reasonable being.

While a formal system does not tolerate any exterior intervention, because it is closed, because the elements which constitute it are given once and for all, because its basic principles and rules of inference are beyond discussion, the intervention of a third party can add nothing new, unless aiming to replace the system by another. It is altogether different in the case of law, and it is also different in philosophy.

12 Cf. Ch. Perelman, op. cit. supra note 7, at 88 and 92. 
The philosopher, like the judge, has an interest in hearing the opposing points of view before making a decision. In fact, his role is not simply to describe and explain the real, in the manner of the scientist who aims at objectivity, but he must take a position concerning the real. His ontology is not simply description of the real, but articulates the hierarchy of its manifestations. ${ }^{13}$ Rationality is linked to values which he would want not only common but also universal, hoping that they would obtain the adherence of the universal audience, that is, the audience composed of all men both rational and competent. ${ }^{14}$ But, never being sure of the universality of his norms and his values, the philosopher must always be ready to listen to the objections which could be proposed to him and to take them into account, if he cannot refute them. The dialogue should be open, for he can never consider the theses he advocates as being definitive. If in law the need to establish an order requires that certain authorities have the power of decision, it is not the same in philosophy. There does not exist, in philosophy, an authority capable of according to certain theses the status of res judicata. ${ }^{15}$

After having sought, for centuries, to model philosophy on the sciences, and considered each of its particularities as a sign of inferiority, perhaps the moment has come to consider that philosophy has many traits in common with law. A confrontation with the latter would permit better understanding of the specificity of philosophy, a discipline which is elaborated under the aegis of reason, but a reason which is essentially practical, turned toward rational decision and action.

\footnotetext{
13 Cf. Ch. Perelman, Justice and Justification, 10 Natural Law Forum 16-17 (1965).

14 For the idea of universal audience (l'auditoire universel), cf. Ch. Prrelman and $L$. Olarechts-Tyteca, Traité de L'Argumentation paragraphs 6-9 (1958).

15 Perelman, op. cit. supta note 8, at 102.
} 